the patient with clear-cut communicating hydrocephalus, the patient with epilepsy, the two patients intoxicated by drugs, the eigh depressed patients, and the patient with mania. If we had wished to press the point we might have included 24 other patients in whom the results of investigation could have led to some attempt to treat the patients or their relatives; that is, treatment for the seven hypertensive patients with arteriosclerotic dementia, treatment for the six alcoholics, genetic counselling for the relatives of three patients with Huntington's chorea, symptomatic therapy for the five patients with malignant brain tumours, and even experimental antiviral treatment for the three patients with Creutzfeldt-Jacob's disease.-We are, etc.,

C. D. MARSDEN

Department of Neurology

Institute of Psychiatuy and

King's Colhege Hospital Medical School,

London S.E.S

M. J. G. HARRISON

National Hospital for Nervous Diseases,

London W.C.1

\section{Abortion and Miscarriage}

SIR,-It is surely time that we abandoned the term "abortion" as a synonym for the lay term "miscarrage." And this for two reasons. First, while it is the function of language to impart information, I find I no longer know what it means when general practitioner writes to me that his patient had an abortion last year. As a result I have the embarrassing task of having to ask the patient whether this was an accident that she bitterly regrets, or whether this was a procedure she requested. The second reason is that patients are objecting even more strongly than ever to the appearance of the word "abortion" in the obstetric history part of their antenatal notes. Years ago it was easy to explain that this was merely a medical term for what they called a miscarriage, but of course this explanation is no longer acceptable.

I suggest, therefore, that as a profession we employ the word "miscarriage" in cases where the pregnancy was lost without the known intervention of a helping hand, and "termination of pregnancy" for procedures carried out under the Abortion Act.-I am, etc.,

Thorpe Maternity Hospital

R. F. R. GARDNER

Peterlee, Co. Durham

\section{Epitaph for the M.C.H.C.}

SiR,-The mean corpuscular haemoglobin concentration (M.C.H.C.) obtained from the Coulter " $S$ " machine is not a good index of iron deficiency (16 October 1971, p. 169), but I have found it useful in evaluating the quality of results produced by the machine. A simple calculation based on the definitions of the indices shows that M.C.H.C. $\equiv \frac{\text { M.C.H }}{\text { M.C.V. }}$

Thus, if either the M.C.H. (mean corpuscular haemoglobin) or the M.C.V. (mean corpuscular volume) is inaccurate the M.C.H.C. will tend to depart from the expected range.

Even highly reliable instruments do occasionally become inaccurate and in times of difficulty the $\mathrm{Hb}$ and R.B.C. (hence M.C.H.) results can be checked on other types of instrument. There is no way of checking the M.C.V. because the microhaematocrit obtained manually is different from the Coulter " $S$ " result.

When the M.C.V. standardization, measurement, or calculation is suspect, in spite of correct " $4 \mathrm{C}$ " results, and a series of specimens shows good correlation for $\mathrm{Hb}$ and R.B.C. between the Coulter " $S$ " and other methods, a glance at the M.C.H.C. allows one to judge whether an abnormal M.C.V. is genuine.

\begin{tabular}{c|c|c|c|c|c}
\hline M.C.V. & $\begin{array}{c}\text { False } \\
\text { Low }\end{array}$ & $\begin{array}{c}\text { True } \\
\text { Low }\end{array}$ & $\begin{array}{c}\text { True } \\
\text { Normal }\end{array}$ & $\begin{array}{c}\text { True } \\
\text { High }\end{array}$ & $\begin{array}{l}\text { False } \\
\text { High }\end{array}$ \\
\hline M.C.H.C. & High & Normal & Normal & Normal & Low
\end{tabular}

The M.C.H.C. is a useful addition to the other methods of quality control which are being used.-I am, etc.,

Robert J. Crawford

Department of Haematology,

Southern General Hospital,

Glasgow

Pancreatin as a Source of Hospital-acquired Salmonellosis

SIR,-We noted with concern the report on the presence of salmonella in pancreatin made by vacuum drying and extraction with a fat solvent (13 May, p. 376). We were not particularly surprised, for these organisms are still far too common on animal carcasses, and vacuum drying provides a not unfavourable environment for multiplication. Surface sterilization is undoubtedly a step in the right direction, but we doubt whether it can be as effective as the alcohol sterilization technique we use routinely in the preparation of all our pancreatin. (Pat. Appn. 30600/69.)

The result of applying our standard manufacturing process to highly contaminated raw material in the laboratory was as follows:

\begin{tabular}{lc}
\hline \multicolumn{2}{c}{ Before Stage 2* } \\
$\left.\begin{array}{lc}\text { Coliforms } & 7 \times 10^{4} \\
\text { Streptococci } & 3 \times 10^{4} \\
\begin{array}{l}\text { E. coli } \\
\text { Pseudomonas }\end{array} & >1 / g \times 10^{4}\end{array}\right\}$ & After Stage 2 \\
\hline
\end{tabular}

(*Stage 2 is treatment of the homogenized pancreas with alcohol).

We consider that pancreatin manufactured by this process could present no danger to health from the presence of salmonellae. Tests on $25 \mathrm{~g}$ samples of thousands of batches confirm our opinion, for we have never once detected salmonellae.-We are, etc.

H. F. Frost Director of Research

G. FARKAS Chief Bacteriologist,
Weddell Pharmaceuticals Ltd.

London E.C.1

\section{Controlled Drinking for Alcoholism}

SIR,-Dr. S. Rachman (3 June, p. 591) misses the point. Relapse is not just a "bout of excessive drinking;" this is merely the overt expression of the relapse process. The actual relapse precedes the bout of drinking and is in fact the decision to start drinking. This has been confirmed experimentally and confirmed clinically by the fact that patients taking disulfiram (Antabuse) who relapse stop taking their disulfiram two or three days before starting to drink. If behaviour therapy is to be considered, since it is apparently easier to abstain than to control drinking, then behaviour therapy should be directed to strengthen abstention rather than to monitor controlled drinking. Abstinent alcoholics who have had many relapses will tell you that it is in fact easier not to take the first drink than to stop drinking after one or two drinks.

While I agree with the implication that total abstention need not be the entire goal in the treatment of alcoholics, in our present state of knowledge abstention should still be part of the advice we offer to our alcoholic patients.

The observations of Davies ${ }^{2}$ that some alcoholics are capable of returning to a life of social drinking may be based on the explanation that this group of alcoholics are basically suffering from depression. At the alcoholic unit in this hospital we are investigating this possibility by studying the distribution of body potassium in alcoholics and also by a controlled trial of the effects of lithium carbonate on the relapse rate of alcoholics who have a definite history of depression. It may be that the Davies' cohort were alcoholic patients who have had depressive illnesses, but when in remission no longer need to drink alcohol as an attempt at self-medication, but can once again use alcohol socially.-I am, etc.,

West Park Hospital,

JULIUS MERRY Epsom, Surrey

Merry, J,, Lancet, 1966, 1, 1257 Alcoholism, 1962, Q 23 , 94 . Fournal of Studies on

\section{Donors for Organ Grafting}

SIR,-Dr. E. Poole (6 May, p. 350) does not like our definition of "irreversible brain damage" (1 April, p. 48). The latter referred to a paper which has since appeared in the Solicitors' fournal (28 April), in which it is made quite clear that the brain damage combined with unconsciousness was both prolonged and widespread. Our full consideration would clearly preclude such conditions as cerebral thromboses and cerebral abscesses, from which improvement normally occurs. We think that this point is quite clear in our full length paper.-We are, etc.,

HaRold HillmaN

Unity Laboratory,

Department of Biological Sciences,

University of Surrey

London E.C.4

T. M. AldRIDge

\section{Severe Toxaemia of Pregnancy}

SIR,-Dr. J. E. F. Pohl and others are to be congratulated on their successful management of four cases of severe toxaemia (3 June, p. 568). However, their presentation is unduly flattering to the diazoxide used in management, and probably pays insufficient tribute to the quality of the monitoring of the fetal condition, which in all the cases appears to have been assessed mainly by the measurement of fetal growth.

In my experience when "hypertension complicates pregnancy and proves resistant 